\title{
How to Highlight Characteristics of Traditional Culture in Construction of Teaching Environment of Artistic Designing Major
}

\author{
Ye $\mathrm{Li}^{1}$ \\ ${ }^{1}$ Nanjing Institute of Industry Technology, Nanjing, China \\ Correspondence: Ye Li, Nanjing Institute of Industry Technology, Nanjing, Jiangsu, China. E-mail: \\ liy1@niit.edu.cn
}

Received: May 14, 2012 Accepted: June 2, 2012 Online Published: August 30, 2012

doi:10.5539/ass.v8n11p229

URL: http://dx.doi.org/10.5539/ass.v8n11p229

Periodical Achievement of 2010 Educational Young People Subject "Study on Heritage and Development of Chinese Traditional Culture in Artistic Designing Teaching in Higher Vocational Schools" of the National Social Science Fund "Eleventh Five-Year" Plan (Subject Approval NO: CLA100169)

\begin{abstract}
Heritage, learning and borrowing of Chinese traditional culture request for certain characteristics of traditional culture in teaching environment. It emphasizes regionalism and national character of the teaching environment, and realizes a diversified teaching mode. It seems quite important in the whole process of teaching how to inherit the modern teaching method of Chinese traditional culture and construct a teaching environment with Chinese traditional cultural connotation. Learning of the traditional culture calls for a consistent and cut-through process and should be integrated into learning and living of students from the several aspects of the campus culture and atmosphere of teaching environment, so as to make traditional culture essentially promote reform and development of artistic designing teaching mode in higher vocational and junior colleges.
\end{abstract}

Keywords: traditional culture, teaching environment, heritage, innovation

In the contemporary society which has been developed rapidly, deficiency of learning of traditional cultural knowledge is obviously an extremely austere problem. As for students majoring in artistic designing in higher vocational schools and junior colleges, it seems quite important to run the quintessence of traditional culture through the entire teaching process. Learning of the traditional culture calls for a consistent and cut-through process and should be integrated into learning and living of students from the several aspects of the campus culture and atmosphere of teaching environment so as to enable students to learn and appreciate the broadness and profoundness of traditional culture from many aspects.

\section{Strengthening and Enriching Construction of Traditional Culture in the University}

It is stipulated in the Twenty-ninth Item of "Culture Development Program during the National 11th Five-Year Plan Period", "We should give full play to the positive functions of festivals and customs, adapt to the contemporary life, embody the feature of the times, take into consideration of activities for construction of spiritual civilization, control the transform and traditions with persistence, continuously innovate forms and enrich content, reform and development folk traditional festival content, customs and etiquette with profound national features and protect basic elements of national culture." At present, we adopt the mode of immersion teaching in understanding of university students majoring in artistic designing in higher vocational and junior colleges in the traditional culture so as to build up an atmosphere of traditional culture in the process of campus construction and is an important approach to enhancing the traditional cultural quality of university students majoring in artistic designing in higher vocational and junior colleges. Students are able to participate in traditional cultural festivals in the true sense and explore the cultural connotation of traditional cultural festivals through the popularity activities of some excellent traditional culture. Students will be edified by the traditional culture naturally and unconsciously in the process of enriching construction of campus culture. 


\subsection{Special Lecture}

According to the different features of traditional culture, we can invite experts to give a lecture with pertinence, realize the significance of traditional culture in the quality-oriented education among students and explain application of traditional cultural elements in modern design. So far as Chinese traditional pattern is concerned, it is a kind of particular ornamentation with skillful conception, full of interest, particular style and profound national characteristics which all represent particular meanings. Since they themselves have particular traditional styling pattern, we can refer to them in the works of plane designs or re-create them with a modern technique of expression to create works of plane designing that originate from traditional patterns and correspond with the modern aesthetics. For example, the station caption of the Phoenix TV is exactly application of the pattern of phoenix in its modern simplification graph.

By the means of special lectures, students are able to come to know about the source, connotation and realistic value of the traditional culture, accept the traditional culture and know about the traditional culture in their psychology so as to achieve the purpose of active learning the traditional culture.

\subsection{Seminar of Special Subject}

In order to stimulate students' enthusiasm in learning the traditional culture and know about the Chinese traditional culture in a correct way, it is necessary to pick up some special subjects for discussion, for which we can mainly discuss from the following several aspects. The first aspect is what the tradition means to us? The second one is how to view the traditional cultural craze that is arising day by day at present? The third one is how to correctly view the currently ongoing national rejuvenation and cultural rejuvenation? Given the above questions, we offer a seminar of special subject for a certain traditional culture, such as, the significance of Chinese auspicious patterns in development of the modern society, the image modeling of Chinese painting and the definition of tradition in Chinese plane designing. Considering these questions, we can decide that they are not only Chinese patterns and figures that have been passed down for the past several thousand years, but mainly refer to the Chinese national character embodied in the plane designing, namely, the thinking mode and cultural and psychological accumulation of Chinese people.

For such a seminar of special subject, it is necessary for students to collect and sort out relevant data and analyze the result, which may play an important role in students' learning of the traditional culture in the process of proceeding of a series of activities. Students may also know more deeply about the traditional culture by the means of this kind of seminars of special subjects. The process of material collection and sorting out is the process of learning.

\subsection{Collect Folk Songs of Special Subject}

It is necessary for us to seek roots for the source of the traditional culture, know about development of traditional culture in the source of origin and experience by ourselves connotation of the culture. We may conduct an on-the-spot investigation on the spiritual connotation that is embodied by Hui Construction, Three Carvings of Hui School and humanities and geography, etc., deeply experience the internal ideas, conduct an on-the-spot research and collect folk songs of special subject in the aspects of historical value, realistic significance and style and characteristics, etc., and strengthen understanding and knowledge of university students in the traditional culture. The forms of collecting folk songs of special subjects are various and students may experience the folk customs and habits, construction styles and cultural characteristics of different regions. Since the cultural connotation runs through all the aspects of clothing, food, shelter and transportation, we may explore the essence of traditional culture from multiple angles to let students accept and understand the traditional culture from the sources of the culture by means of collecting folk songs of special subjects.

The styles of Chinese traditional culture are various, so we can search for a path exploring the traditional culture according to the place of birth of Chinese traditional culture, collect a series of folk songs of special subjects for Chinese traditional culture and form a systematic and particular cultural path.

\subsection{Salon of Special Subject}

Chinese people have created a lot of particular traditional objects in their daily life, such as, the primitive colored pottery utensils, the knife money in Qin Dynasty, the traditional shadow play, the silver ingot in Qing Dynasty and so on, which extensively contain any representative traditional object that Chinese people have contacted in the daily life at all the historical periods and borrowing and applying the design of their image may largely enhance the ethnic characteristics and historical complex of the plane works. The traditional culture can be learnt by the means of being delighted to see and hear among students so as to enable students to not only learn cultural knowledge and improve their cultural quality, but also to receive severe test of the traditional cultural spirit and 
edify their spiritual sentiment. A series of activities may exhibit to students the platform of Chinese traditional culture so as to achieve the ultimate purpose of strengthening higher vocational and junior college students' implication in learning Chinese traditional culture, greatly enrich the cultural life of university students and enhance the personal quality of students majoring in artistic designing in higher vocational and junior colleges.

It is necessary to launch activities in combination with Chinese traditional festival culture and conduct a questionnaire survey about Chinese traditional festival culture, such as, which traditional cultural festival do you favor and why? What kind of connotation do Chinese traditional festivals have? You are encouraged to express their own opinions. Whether do you have such a view that the atmosphere is getting worse in celebrating Chinese traditional festivals? And Why? What kind of disadvantages do you think development and innovation of Chinese traditional festivals have or what are the bad aspects do you think? Such as, unnecessary and over elaborate formalities and too many taboos, etc. We want to listen to your opinions. We can organize a discussion for a specific festival and by setting some questions, we can come to know about our students' understanding in the traditional cultural festivals, which is also a process of mutual learning among all of us. In the meantime, it is also possible to make up for disadvantages of students majoring in artistic designing in higher vocational and junior colleges in the aspect of cultural learning.

\subsection{Exhibition on Special Subject}

Chinese traditional cultural arts are quite abundant and a variety of artistic patterns, such as, Chinese calligraphy, carving, paper-cut and embroidery, etc., can all be expressed by different traditional material quality. Such traditional plane arts material elements as Chinese ink, cinnabar, vermilion cyan, wax paper and embroidery can be skillfully allocated and used with modern artistic elements in the process of designing, which can also create modern plane artistic designing works with clear Chinese taste and profound cultural connotation. We can hold exhibitions of related subjects to exhibit our achievements through all the above specific artistic works patterns and also exhibit the ability of students majoring in artistic designing in higher vocational and junior colleges to mater multiple patterns of traditional culture. They are able to embody the profoundness and broadness of the traditional culture from multiple aspects and angles.

It is necessary for students to visit the cultural venues of a variety of art gallery, exhibition hall and folklore museum to enrich their life, broaden their vision of field, know about the trend of cultural development in due course, experience and appreciate the tendency of combination of traditional culture with modern artistic development, stimulate the enthusiasm in learning and creation of students majoring in artistic designing in higher vocational and junior colleges, walk in the front of development of modern arts and traditional culture, keep abreast with the times and tread the hells of artistic culture.

\subsection{Competition on Special Subject}

It is necessary for teachers and students to frequently launch related activities about Chinese traditional culture. A lot of typical tales of marvels in Chinese traditional stories, idioms, proverbs or historical records popular among Chinese folks manifest the excellent Chinese traditional culture to the whole world. We may borrow the content to design a concept and propagandize our excellent traditional national culture at the time of enriching the originality thinking of the design.

We may guide students in participating in the activities of calligraphy competition, ancient poetry recitation contest and lecture of the five millenniums of Huaxia to stimulate students' interest and to encourage them to actively take part in these competitive activities. Through these pertinent competitions, students may be able to know about the cause and effect of Chinese traditional culture and Chinese particular cultural connotation. The various competition means can enable students with different interest and favor to take part in the activities, which helps to enlarge students' scope of learning the traditional culture. Correspondingly, the number of students who take part in the activities increases and the purpose of learning, understanding and accepting the traditional culture is achieved.

\section{Establishing Institutions to Study Traditional Culture}

\subsection{Constructing Corresponding Traditional Cultural Studio Based on Folk Custom Festivals}

We all know that culture is well known for its features. Each territory and each country has its own particular and precious traditional culture. Each of us lives in a certain kind of cultural atmosphere, so whether our behavior, thinking and emotion or our spiritual value orientation may be influenced by the national culture.

Since the traditional festivals are abundant and colorful in content, it is only possible for people to continue to deepen their memory in these festivals by means of personal experiencing. They may combine folk customs and festivals to launch corresponding activities and embody the particularity of folk customs and festivals. For 
example, all the following indicate that different festivals have different meanings: calamus, pouch, wormwood, realgar liquor and the silk with five colors in the Dragon Boat Festival, rabbit God and moonlight paper in the Mid-autumn Festival and cornel and chrysanthemum, etc., in the Double Ninth Festival. We can set up cultural studios of related subjects by referring to the particularity of the festivals and let the cultural charm of folk customs and festivals silently influence students' soul unconsciously. There exists knowledge around us that the traditional cultural festivals can trace. We may launch corresponding activities in the traditional cultural studio according to a particular festival and students may know about the traditional cultural festivals from multiple angles through the multiple forms of activities. Then, we may avoid letting a lot of traditional cultural festivals be left without anybody to care for. When we have the consciousness to do a relevant thing, it is just a process of learning. With the traditional cultural festival studio, we may enable students to change from doing it with consciousness to accepting it naturally, which is also a process of learning the leap of the traditional culture. The particular situationality, infectivity, practice and entertainment of folk custom festival education may help students to take an initiative in taking part in a practical activity in a natural, loose and enjoyable atmosphere and to give full play to the function of traditional cultural studio.

\subsection{Highlighting Characteristics of Traditional Culture in Construction of Teaching Environment}

Emphasis on the regional and national features of the teaching environment and realization of a diversified teaching mode in China is to require educators to inherit and borrow Chinese traditional culture and create a teaching environment that is characteristic of traditional Chinese cultural features. How to inherit the modern teaching method of Chinese traditional culture, construct a teaching environment with characteristics of Chinese traditional cultural connotation for the modern educational mode in China under the profound influences of western concepts is an aspect that has to be paid enough attention to in order to promote the modern education to realize diversification, get rid of the stale and bring forth the fresh, possess the local characteristics at the time of walking towards the world and continue to be enriched and improved, which is also a status quo that the education and teaching environment of artistic designing in higher vocational and junior colleges in China is urgent to be changed.

We may change the atmosphere of the teaching environment by taking into consideration of the curriculum work of relevant courses. For example, at the end of the course of "Research of Traditional Patterns", the work of students about research of traditional patterns can be shown in the showcase and in the classroom, so as to create an atmosphere of creating the traditional cultural education in the environment. In the process of construction of a teaching room, we can also pioneer a special teaching occasion to propagandize and decorate traditional culture, to influence students by what they see and hear, and to get the traditional culture more widely propagandized and to feel as if they have walked into the long river of the history of the traditional culture when they walk into the teaching room.

\subsection{Making Effective Use of Social Resources and Establishing Cooperative Relationship with Relevant Cultural Units}

The scope of education of the traditional culture should not be merely confined to the internal campus. We can also refer to the experience of constructing educational bases for youngsters all over the world, take advantages of the museum, exhibition hall, park, cultural relics, places of interest and the occasions of all sorts of existing educational bases to further broaden students' educational channel, make the educational resources that have been neglected in the past enter the mainstream channel of higher education, let them become the abundant, intuitive and vivid extracurriculum classroom of university students and promote the cultural identity and deepening of knowledge of university students.

We may make full use of more extensive social resources to provide our students with a base of learning, visiting and practicing the traditional culture. Nanjing Folk Customs Museum regards educational institutions as the key of extension of social education work and has had alliance connection with several universities to bring folk custom knowledge into the classroom and take the exhibitions into the school. It has successively held exhibition tours about traditional culture in several universities to enlarge its purpose of propagandizing the cultural connotation of the traditional culture. Full and rational usage of resources of the traditional cultural units and enlarging acquisition of traditional cultural knowledge by students should not only be limited to the classroom and the school. Establishment of a cooperative relationship with traditional cultural units can enlarge students' scope in learning the traditional cultural knowledge and broaden their vision of field. At the same time, it is the relevant traditional cultural units that can really realize the significance of survival of the traditional culture and let more descendants of the Chinese Nation know about the broadness and profoundness of Chinese traditional culture. It is exactly where the significance of cultural heritage lies. If the Chinese people do not learn and accept 
these cultures, then the significance of their existence deserves our reflection. It is necessary for us to make full use of and learn the connotation of Chinese traditional culture and realize more value and significance of the traditional culture in the modern society in which it is developed rapidly.

\section{Concluding Remarks}

Dissemination of culture is not completed in one day and it needs a process, which we are required to accumulate bit by bit by all kinds of means, and which requires to educate students by all kinds of means in our daily teaching, some of which may come from teachers and some of which may come from books. If we highlight the characteristics of culture in the teaching environment, then we can make students penetrate into the traditional culture. We can also provide guidance about traditional culture by the internal and external means, so that our students are more likely to accept the traditional culture.

\section{References}

Wang, Qian. (2000). Innovative Function of Chinese Traditional Culture. Journal of Northeastern University (Social Science), (04).

Yan, Xiuzhi. (2003). Theoretical Discussion on the Innovation of Traditional Chinese Culture. Journal of Dali College, (06).

Yao, Dian. (2008). Meditating and exploring innovation on traditional culture in higher education. Journal of Yichun College, (05).

Zhang, Siwei. (2006). On Construction of Campus Culture in Higher Vocational Institutions. Education and Vocation, 14. 